\title{
Evaluation of Methods of Resynchronization for Insemination in Cows of Unknown Pregnancy Status
}

\author{
K. N. Galvão, ${ }^{\star 1}$ J. E. P. Santos, ${ }^{2}$ R. L. Cerri, ${ }^{,}$R. C. Chebel, ${ }^{\star}$ H. M. Rutigliano, ${ }^{*}$ \\ R. G. Bruno, ${ }^{\star}$ and R. C. Bicalho† \\ *Veterinary Medicine Teaching and Research Center, University of California-Davis, Tulare 93274 \\ †Department of Population Medicine and Diagnostic Sciences, College of Veterinary Medicine, Cornell University, Ithaca, NY 14853
}

\begin{abstract}
The objectives of this study were to evaluate the effect of 3 methods of resynchronization of estrus and ovulation for lactating dairy cows of unknown pregnancy status on conception rate and time to pregnancy. Holstein cows ( $\mathrm{n}=495)$ were randomly assigned to 1 of 3 treatments: 1 ) control $(\mathrm{n}=167)$, resynchronization with a timed AI protocol upon diagnosis of nonpregnancy on d 31 after preenrollment AI (PAI); 2) CIDR-G ( $\mathrm{n}=159)$, use of an intravaginal progesterone insert from $d 14$ to 21 after AI, with $\mathrm{AI}$ at estrus from d 21 to 24 and initiation of a timed AI protocol on d 24 after AI in cows not reinseminated; 3) CIDR-G + ECP ( $n=169)$, the same treatment as CIDR-G but with an injection of 1 $\mathrm{mg}$ of estradiol cypionate at the time of progesterone insert removal. Cows were continuously reenrolled in the same treatment until diagnosed as pregnant, which resulted in a total of 1,148 AI (495 PAI and 653 resynchronized AI; RAI). Blood was collected from 1,001 cows on d 14, 21, and 24 after each AI for analysis of progesterone, and ovaries were scanned on d 21,24 , and 31 after AI. The presence of an active corpus luteum was presumed based on progesterone $\geq 1 \mathrm{ng} / \mathrm{mL}$. Pregnancy was diagnosed by ultrasonography on d 31 and 61 after AI. The presence of an active corpus luteum and the incidence of luteolysis were similar for all treatments from $d 14$ to 24; however, luteolysis increased in the CIDR-G + ECP treatment from d 21 to 24. Conception rates for the PAI and all AI were similar on d 31 and 61 after insemination. Conception rates at 31 and 61 $\mathrm{d}$ after the RAI were also similar among treatments. Overall pregnancy loss for the PAI, RAI, and all AI were similar for all treatments. The accuracy of estrous detection, based on progesterone concentration within $2 \mathrm{~d}$ of detection of estrus, was similar for all treatments
\end{abstract}

\footnotetext{
Received February 8, 2007.

Accepted May 11, 2007.

${ }^{1}$ Present address: Department of Clinical Sciences, College of Veterinary Medicine, Cornell University, Ithaca, NY 14853.

${ }^{2}$ Corresponding author: Jsantos@vmtrc.ucdavis.edu
}

for the RAI and averaged 95.3\%. The estrus-detection rate (EDR) decreased for the CIDR-G and CIDR-G + ECP treatments from d 14 to 21, but increased from d 21 to 24 compared with control cows; however, the EDR was smaller for cows in the CIDR-G treatment during the entire resynchronization period compared with those in the CIDR-G + ECP and control groups. The reinsemination interval was reduced in cows receiving the CIDR-G + ECP treatment compared with control cows because of increased EDR after removal of the intravaginal insert; however, the interval from study enrollment to pregnancy was not different among treatments. These results indicate that the reproductive performance of dairy cows did not differ among the 3 resynchronization treatments evaluated.

Key words: dairy cow, estradiol cypionate, progesterone, resynchronization

\section{INTRODUCTION}

Detection of estrus is one of the major challenges in the reproductive management of dairy cows (Lopez et al., 2004). Higher producing dairy cows have reduced expression and duration of estrus, and these effects have been attributed to decreased circulating concentrations of estradiol in spite of a larger preovulatory follicle diameter (Lopez et al., 2004). Because detection of estrus is insufficient to ensure high insemination rates in lactating dairy cows, timed AI following protocols for synchronization of ovulation (Pursley et al., 1995; Pancarci et al., 2002) have become common practices for reproductive management in dairy herds (Caraviello et al., 2006). Implementation of a timed AI protocol after the first postpartum insemination, however, is only possible after detection of nonpregnancy in cows. Programs for timed AI involve synchronization of ovulation after induced luteolysis, which can only be implemented in cows that are not pregnant. A large proportion of cows that do not conceive after AI may not be observed in estrus, and reinsemination would occur only after a diagnosis of nonpregnancy, which usually occurs after $35 \mathrm{~d}$ following the preceding AI. 
A controlled internal drug-releasing (CIDR) insert impregnated with $1.38 \mathrm{~g}$ of progesterone was recently approved for use in lactating dairy cattle in the United States, with the purpose of synchronizing the return to estrus. Chenault et al. (2003) reported that use of the CIDR insert from 14 to $21 \mathrm{~d}$ after AI improved synchronization of the return to estrus and increased the proportion of nonpregnant cows reinseminated before a pregnancy diagnosis, with no effect on resynchronized conception and pregnancy rates, but with a reduction in conception rates for the initial AI. El-Zarkouny and Stevenson (2004) observed an increased synchronization of return to estrus in 1 of 2 experiments, but failed to detect any difference in overall estrous detection following use of the CIDR insert. No difference was observed for the preenrollment and resynchronized conception rates with the intravaginal insert, but cows receiving the CIDR insert had greater embryo survival between 29 and $57 \mathrm{~d}$ after AI. In the second experiment by the same authors (El-Zarkouny and Stevenson, 2004), administration of estradiol to cows treated with a CIDR at insert removal numerically increased the proportion of nonpregnant cows that returned to estrus (58.6 vs. $44.6 \%$ ). A recent study corroborated the findings by El-Zarkouny and Stevenson (2004) and also revealed an increased embryonic survival when cows were treated with an intravaginal progesterone insert between 14 and $21 \mathrm{~d}$ after AI (Chebel et al., 2006). Therefore, it is possible that use of the CIDR might improve the resynchronization of return to estrus in nonpregnant cows and increase embryonic survival in pregnant cows. Furthermore, it is possible that incorporation of an estradiol injection at CIDR removal may increase expression of estrus in high-producing dairy cows, which typically have reduced estradiol concentrations at estrus (Lopez et al., 2004), but without harming the established pregnancy (El-Zarkouny and Stevenson, 2004).

Another method of expediting reinsemination of cows of unknown pregnancy status is to synchronize follicle development by initiating the ovulation synchronization protocol $7 \mathrm{~d}$ before pregnancy diagnosis with administration of $\mathrm{GnRH}$, and subsequently completing the protocol after diagnosis of nonpregnancy (Chebel et al., 2003; Fricke et al., 2003). This procedure had no negative effect on the established pregnancy and did not alter conception rates following resynchronization when GnRH was given on d 21 or later after the preenrollment AI. Treatment with GnRH $7 \mathrm{~d}$ before pregnancy diagnosis might expedite reinsemination of nonpregnant cows as long as it does not suppress expression of estrus (Chebel et al., 2003) or influence embryo survival following the resynchronized AI (Fricke et al., 2003).
The objectives of this study were to evaluate 3 methods to resynchronize estrus and ovulation in lactating dairy cows of unknown pregnancy status on synchrony of return to estrus, overall return to estrus, reinsemination interval, conception rates, pregnancy loss, and time to pregnancy. In particular, we were interested in determining whether methods that improve the synchrony of return to estrus in nonpregnant cows in conjunction with initiation of the timed AI $7 \mathrm{~d}$ before a diagnosis of nonpregnancy would influence the time to pregnancy in cows subjected to the same treatment throughout the study period.

\section{MATERIALS AND METHODS}

\section{Animals, Housing, and Feeding}

The University of California-Davis Institutional Animal Care and Use Committee approved all procedures involving the cows used for this study. A total of 495 lactating Holstein cows (141 primiparous and 354 multiparous) from a commercial dairy farm located in the Central Valley of California were initially enrolled in the study on d 14 after the preenrollment AI. All cows in the herd that were eligible to be inseminated and were 12 to $15 \mathrm{~d}$ (median = 14) after AI were enrolled in the study. The cows were between 74 and 393 DIM (median $=90)$, and 59, 16, and $25 \%$ were enrolled after the first, second, or third or more postpartum AI (range $=1$ to 10 ). For the first postpartum AI, cows were submitted to a presynchronized-timed AI protocol (Pancarci et al., 2002) with $2 \mathrm{PGF}_{2 \alpha}$ injections given 14 d apart on $d 39 \pm 3$ and $53 \pm 3$ postpartum and the timed AI protocol initiated $14 \mathrm{~d}$ later, on $\mathrm{d} 67 \pm 3$, with the timed AI performed on $\mathrm{d} 77 \pm 3,48 \mathrm{~h}$ after the estradiol cypionate injection. For the subsequent AI, cows were either inseminated upon detection of estrus based on removal of tail chalk (Macmillan et al., 1988) or after resynchronization with the same timed AI protocol (Pancarci et al., 2002), which was initiated upon detection of nonpregnancy without presynchronization. Cows were enrolled in the study from January to July 2004 and the study was completed in September of 2004.

The number of lactating cows in the herd during the study was 880 , and the $3.5 \%$ FCM rolling-herd average for the year of 2004 was $11,700 \mathrm{~kg} / \mathrm{cow}$, with average $( \pm$ SD) daily milk yield for the enrolled primiparous and multiparous cows during the study period of $33.0 \pm 4.9$ and $47.3 \pm 6.8 \mathrm{~kg} / \mathrm{d}$, respectively. Twice daily, cows were fed the same TMR, formulated with CPM Dairy software (version 3.0.8, 2006) and evaluated with NRC (2001) software to meet or exceed the dietary requirements for a lactating cow weighing $680 \mathrm{~kg}$ and produc- 


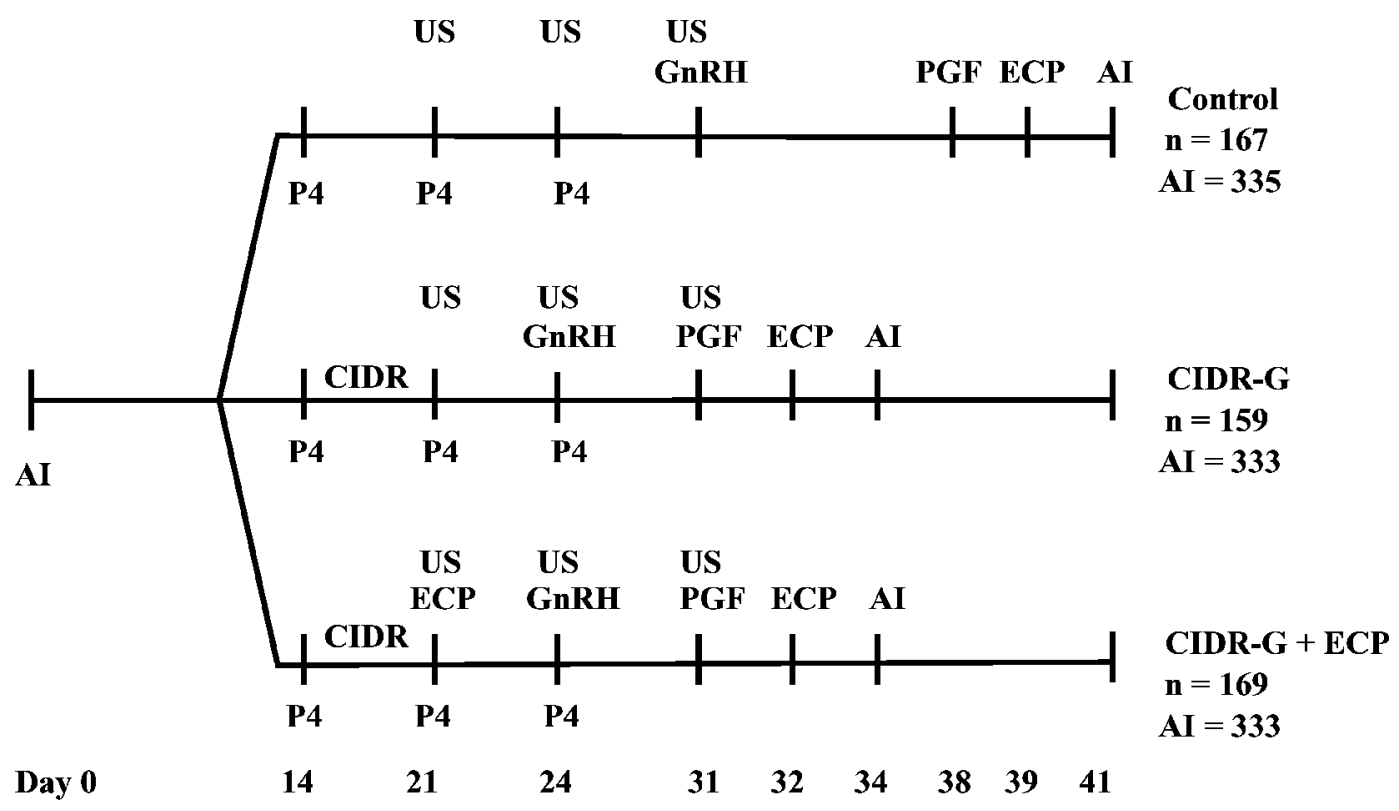

Figure 1. Diagram of activities during the study. AI = artificial insemination; CIDR = controlled internal drug-releasing insert containing progesterone used for $7 \mathrm{~d}$; ECP = injection of $1 \mathrm{mg}$ of estradiol cypionate; $\mathrm{GnRH}=$ injection $100 \mu \mathrm{g}$ of gonadotropin-releasing hormone; P4 = blood collection for analysis of progesterone concentration; $\mathrm{PGF}=$ injection of $25 \mathrm{mg}$ of prostaglandin $\mathrm{F}_{2 \alpha}$; US = ultrasonographic examination of ovaries. Control = reinsemination upon detection of estrus between d 14 and 31 after AI or resynchronization with a timed AI protocol upon diagnosis of nonpregnancy on d 31 after AI; CIDR-G = insertion of CIDR from d 14 to 21 after AI, with AI at estrus from d 21 to 24 and initiation of the timed AI protocol on d 24 in those not in estrus; CIDR-G + ECP = same treatment as CIDR-G but with an injection of $1 \mathrm{mg}$ of estradiol cypionate at the time of intravaginal insert removal.

ing $45 \mathrm{~kg}$ of $3.5 \% \mathrm{FCM}$ when consuming $24 \mathrm{~kg} / \mathrm{d}$ of DM (NRC, 2001).

Cows were housed in free-stall barns equipped with fans and sprinklers that were activated when the environmental temperature rose above $26^{\circ} \mathrm{C}$. Primiparous and multiparous cows were housed in separate pens throughout the study. Cows were milked twice daily, and yields of milk were measured for individual cows once monthly during the official California DHIA milk test performed by the laboratory in Hanford, California. Average milk yield during the first 3 mo postpartum was used to determine the effect of milk yield on reproductive responses. All cows had their body condition scored on a 5 -point ( $1=$ thin to $5=$ fat) system (Ferguson et al., 1994) on d 14 after each AI.

\section{Treatments and $\mathrm{Al}$}

Twice weekly, on Thursdays and Sundays, a cohort of 10 to 40 cows past $74 \mathrm{~d}$ postpartum and between 13 and $15 \mathrm{~d}$ (on Thursday) or between 12 and $15 \mathrm{~d}$ (on Sunday) after AI (median = 14) were blocked according to lactation number $(1,2$, or $\geq 3)$, number of $\mathrm{AI}$ ( 1,2 , or $\geq 3$ ), and days postpartum (median $=90$; range $=74$ to 393). Within each block, cows were randomly assigned to 1 of 3 resynchronization treatments (Figure 1): 1) control $(\mathrm{n}=167)$, reinsemination of cows starting $14 \mathrm{~d}$ after AI upon detection of estrus and resynchronization with a timed AI protocol after diagnosis of nonpregnancy on d 31 (median $=31$; range $=30$ to 33 ) after AI; 2) CIDR-G ( $\mathrm{n}=159$ ), resynchronization with a CIDR insert (Eazi-Breed CIDR Cattle Insert, Pfizer Animal Health, New York, NY) inserted on d 14 and removed on $\mathrm{d} 21$ (median $=21$; range $=19$ to 22 ) after AI, followed by initiation of the timed AI protocol $3 \mathrm{~d}$ (for cows enrolled on Thursdays) and $4 \mathrm{~d}$ (for cows enrolled on Sundays) after removal of the CIDR insert, which corresponded to $\mathrm{d} 24$ (median $=24 ;$ range $=23$ to 26 ) after AI; 3) CIDR-G + ECP ( $n=169)$, same as the CIDR-G treatment, but it included an injection of $1 \mathrm{mg}$ of estradiol cypionate (ECP, $2.0 \mathrm{mg} / \mathrm{mL}$, Pfizer Animal Health) at insert removal. After reinsemination, the treatments were reapplied to the cows (median $=2$ times; range = 1 to 6 times) until they were diagnosed as pregnant on $31 \mathrm{~d}$ after AI or completion of the study period. Therefore, 1,001 cows (495 from the initial AI plus 506 after reinsemination) received the treatments starting $14 \mathrm{~d}$ after $\mathrm{AI}(335,333$, and $333 \mathrm{AI}$ for the control, CIDR-G, and CIDR-G + ECP treatments, respectively). After the last reenrollment in the respective treatments, 147 cows that were reinseminated no longer received the CIDR, GnRH, and ECP and the information from these cows was included in the analyses of data for the resynchronized AI. Therefore, a total of 1,148 AI were per- 
formed: 495 cows with their respective initial AI plus 506 resynchronized AI that received the treatments on d 14 after insemination, and an additional 147 resynchronized AI, which corresponded to the final insemination before the conclusion of the study period when cows no longer received the treatments on $\mathrm{d} 14$. Thus, the total number of resynchronized AI was 653 (506 resynchronized AI that received the treatments starting 14 $\mathrm{d}$ after AI plus 147 resynchronized AI that did not receive the resynchronization treatments). Throughout the manuscript, the initial AI ( $\mathrm{n}=495 \mathrm{AI})$ before treatments were applied are referred to as preenrollment AI (PAI), and all the reinseminations that resulted from the resynchronization treatments $(\mathrm{n}=653 \mathrm{AI})$ are referred to as resynchronized AI (RAI). All the inseminations that preceded the administration of treatments starting on $\mathrm{d} 14$ after $\mathrm{AI}(\mathrm{n}=1,001 \mathrm{AI})$, which excluded the 147 that did not receive the resynchronization treatments before the conclusion of the study, are referred to as all AI.

At the time of insert removal for the CIDR-G and CIDR-G + ECP treatments, the mucus adhering to the insert was evaluated and scored $(1=$ no mucus; $2=$ clear mucus; 3 = cloudy mucus; 4 = yellow mucus, and $5=$ red or brown mucus) as previously reported (Chenault et al., 2003).

The timed AI protocol consisted of a $100-\mu \mathrm{g}$ injection of GnRH i.m. (Cystorelin, $50 \mu \mathrm{g} / \mathrm{mL}$ gonadorelin diacetate tetrahydrate, Merial Ltd., Iselin, NJ), followed $7 \mathrm{~d}$ later by an i.m. injection of $25 \mathrm{mg}$ of $\mathrm{PGF}_{2 \alpha}$ (Lutalyse, $5 \mathrm{mg} / \mathrm{mL}$ dinoprost tromethamine, Pfizer Animal Health), and $24 \mathrm{~h}$ later by an i.m. injection of $1 \mathrm{mg}$ of ECP, with timed AI performed $48 \mathrm{~h}$ after the ECP injection (Pancarci et al., 2002). Cows were observed for signs of estrus once daily, in the afternoon, by removal of tail chalk (Macmillan et al., 1988), which was applied daily with paint sticks (All-weather Paintstik, LA-CO Industries, Chicago, IL). Cows observed in estrus were inseminated on the same day. Therefore, in all treatments, cows were reinseminated either after detection of estrus or at a fixed time. Three technicians inseminated all cows with semen from different sires randomly assigned to the 3 treatments to maintain an equal distribution across treatments.

\section{Blood Sampling for Progesterone Analysis}

Blood samples were collected from all cows that received the resynchronization treatments $(\mathrm{n}=1,001 \mathrm{AI})$ immediately before CIDR insertion (d 14 after AI), CIDR removal (d 21), and GnRH injection (d 24). On d 21, samples were collected $30 \mathrm{~min}$ after CIDR removal. Control cows were sampled concurrently with CIDR-G and CIDR-G + ECP cows. Approximately $7 \mathrm{~mL}$ of blood was collected by puncture of the median coccygeal vein or artery by using evacuated tubes (Vacutainer, Becton, Dickinson and Company, Franklin Lakes, NJ) containing $\mathrm{K}_{2}$ EDTA. The samples were immediately placed in ice, and later centrifuged at $2,000 \times g$ for 15 min to harvest blood plasma. Plasma samples were frozen at $-25^{\circ} \mathrm{C}$ until later analysis of progesterone concentration. Progesterone was analyzed by ELISA according to Galvão et al. (2004). Efficiency of progesterone extraction averaged $86.4 \%$ and the sensitivity of the assay was $0.05 \mathrm{ng} / \mathrm{mL}$. Samples were analyzed in duplicate and the intraassay coefficients of variation (CV) for all samples averaged 6.3\%. A plasma sample of known progesterone concentration $(2.5 \mathrm{ng} / \mathrm{mL})$ was used to determine the interassay CV, which was $9.6 \%$. Individual samples with CV $>15 \%$ between duplicates were reanalyzed. Microplates with interassay $\mathrm{CV}>15 \%$ were also reanalyzed.

Data for progesterone concentrations were later dichotomized as $\geq 1$ or $<1 \mathrm{ng} / \mathrm{mL}$ to evaluate the effect of resynchronization treatments on the presence of an active corpus luteum (CL) and incidence of luteolysis. Cows having a progesterone concentration $\geq 1 \mathrm{ng} / \mathrm{mL}$ at any time point were assumed to have an active CL, and a drop in progesterone concentration from $\geq 1$ to $<1 \mathrm{ng} /$ $\mathrm{mL}$ between 14 and $21 \mathrm{~d}$ or 21 and $24 \mathrm{~d}$ after AI was indicative of luteolysis, as previously reported (El-Zarkouny and Stevenson, 2004).

Concentrations of progesterone were also used to estimate the accuracy of estrus detection for cows returning to estrus from enrollment to pregnancy diagnosis on $d$ 31. Estrus was considered to be accurately diagnosed if the progesterone concentration of a sample collected within $2 \mathrm{~d}$ of detection was $<1 \mathrm{ng} / \mathrm{mL}$, and was considered to be inaccurate if it was $\geq 1 \mathrm{ng} / \mathrm{mL}$. Of the 359 cows that returned to estrus between $\mathrm{d} 14$ and 31 after AI, 316 returned within $2 \mathrm{~d}$ of the blood sampling for progesterone measurement (108, 97, and 111 for control, CIDR-G, and CIDR-G + ECP cows, respectively), and these cows were used for analysis of the accuracy of estrus detection.

\section{Ovarian Ultrasonography and Ovulatory Responses}

Ultrasonographic examination of the ovaries was performed with a 7.5-MHz linear transducer (Sonovet 2000, Universal Medical System, Bedford Hills, NY) on d 21, 24, and 31 after all AI (Figure 1). A map of each ovary was drawn to include the location and size of follicles greater than $5 \mathrm{~mm}$ and CL. Ovulation between d 14 and 21 was determined when the concentration of progesterone was $<1 \mathrm{ng} / \mathrm{mL}$ on d 14 , but $\geq 1 \mathrm{ng} / \mathrm{mL}$ on d 21. Ovulation was also determined to have happened between d 14 and 21 when no follicle $>9 \mathrm{~mm}$ and CL 
were present at ultrasonography on $\mathrm{d} 21$ but a CL was observed on d 24. Between d 21 and 24 , ovulation was determined by the disappearance of a large follicle that was present on $\mathrm{d} 21$ after $\mathrm{AI}$ and appearance of a new CL on the examination on d 31 after AI. Ovulation between $\mathrm{d} 24$ and 31 after AI was determined by the disappearance of a large follicle that was present on $d$ 24 after AI and appearance of a new CL on the ultrasonography examination on d 31 after AI. Incidence of ovulation was evaluated only for RAI, and the data from pregnant cows on $\mathrm{d} 31$ were not considered during statistical analysis.

\section{Pregnancy Diagnosis, Pregnancy Loss, and Reproductive Performance}

All cows were examined for pregnancy by ultrasonography on d 31 after AI. Detection of an embryonic vesicle with a viable embryo in which heartbeat was visualized was used as indicator of pregnancy. Cows diagnosed as pregnant on $\mathrm{d} 31$ were palpated per rectum for detection of an embryonic vesicle to confirm pregnancy $30 \mathrm{~d}$ later, at $61 \mathrm{~d}$ after $\mathrm{AI}$ (median $=61$; range $=58$ to 64 ). Conception rate was defined as the number of pregnant cows divided by the number inseminated in each treatment. Cows diagnosed as pregnant on d 31 and diagnosed as nonpregnant on d 61 were considered to have experienced late embryonic or early fetal loss.

\section{Statistical Analyses}

The experimental design was a randomized complete block design. Twice weekly, on Thursdays and Sundays, a cohort of cows was blocked as described previously and randomly assigned to 1 of 3 treatments. Once assigned to a treatment, the cow was reenrolled in the same treatment until diagnosed pregnant $31 \mathrm{~d}$ after AI or until the completion of the study. This allowed us to examine the effect of treatment on time to pregnancy.

Conception rates were evaluated for the PAI ( $\mathrm{n}=$ 495), the RAI ( $\mathrm{n}=653)$, and all AI $(\mathrm{n}=1,001)$. For the PAI, presence of an active CL on d 14, 21, and 24, incidence of luteolysis from d 14 to 24 , conception rates on $\mathrm{d} 31$ and 61 , and pregnancy losses between 31 to 61 $\mathrm{d}$ after AI were analyzed by the LOGISTIC procedure of SAS (SAS Institute, 2003) because only 1 observation per cow was used. Pregnancy losses for the RAI and all AI were also analyzed by the LOGISTIC procedure of SAS for the same reason. For RAI and all AI, dichotomous outcomes such as presence of an active CL, incidence of luteolysis, estrus-detection rate (EDR), accuracy of estrous detection, incidence of ovulation, and conception rates were analyzed by mixed logistic regression with the GLIMMIX procedure of SAS (SAS Insti- tute, 2003), available for download for version 9.1.3, with cow included in the model as a random effect and treatment as a fixed effect. In analyses with both the LOGISTIC and GLIMMIX procedures, explanatory variables considered for inclusion in the models were parity (primiparous vs. multiparous), BCS ( $<2.75$ vs. $\geq 2.75$ ), AI technician (1, 2, and 3), and milk production (above vs. below the mean milk yield for primiparous and multiparous cows). For conception rates and pregnancy losses for RAI, the models also included the effects of type of AI (AI at estrus vs. timed AI), and if treatments were reapplied $(\mathrm{n}=506)$ or not $(\mathrm{n}=147)$. Explanatory variables were retained in the model when either their main effect or the interaction with treatment resulted in $P \leq 0.15$.

For cows that received the intravaginal progesterone insert (CIDR-G and CIDR-G + ECP), additional analyses were performed to evaluate the effect of mucous score (mucous score 1, 2, and 3 vs. 4 and 5) on conception rates on $\mathrm{d} 31$ and 61 after the RAI and all $\mathrm{AI}$ with the GLIMMIX procedure, and the effect of mucous score on pregnancy loss from d 31 to 61 after AI with the LOGISTIC procedure. Furthermore, for those cows in the CIDR-G and CIDR-G + ECP treatments reinseminated upon detection of estrus, the effects of day after $\mathrm{AI}$ (12 to 15) when the intravaginal progesterone insert was placed into cows on EDR and conception rates were evaluated using the GLIMMIX procedure. A contrast was performed between $d 12$ and 13 vs. $d 14$ and 15 .

The interval between AI was analyzed by ANOVA with the GLM procedure of SAS (SAS Institute, 2003). One CIDR-G and 2 control cows reinseminated and later diagnosed as pregnant were excluded from the analysis of the reinsemination interval.

The hazard ratio for pregnancy was analyzed by Cox's proportional hazard model using the PHREG procedure of SAS (SAS Institute, 2003) for the 495 cows enrolled in the study. The time variable used in the model was the interval in days between the PAI to pregnancy on d 31. Cows that were diagnosed as pregnant to the PAI had a time to conception equal to zero because the date of conception was the date of PAI. Cows remaining nonpregnant at the end of the study were censored. The variables used in the model were treatment, parity, BCS, and milk production, as indicated previously. Treatment was forced into the model, but other explanatory variables were retained only when their main effect or the interaction with treatment resulted in $P$ $\leq 0.15$. The median and mean days to pregnancy were obtained by survival analysis from the Kaplan-Meier model with the LIFETEST procedure of SAS (SAS Institute, 2003). The survival plot was generated with the survival option of MedCalc version 9.2 for Windows (MedCalc Software, Mariakerke, Belgium). Treatment 
Table 1. Effect of the resynchronization protocol on conception rates and pregnancy loss for the preenrollment AI

\begin{tabular}{|c|c|c|c|c|}
\hline \multirow[b]{2}{*}{ Item } & \multicolumn{3}{|c|}{ Treatment $^{1}$} & \multirow[b]{2}{*}{$P$} \\
\hline & Control & CIDR-G & CIDR-G + ECP & \\
\hline Conception rate ${ }^{2}$ & $\longrightarrow$ & $-\%(\mathrm{n} / \mathrm{n})-$ & 年 & \\
\hline $31 \mathrm{~d}$ & $38.3(64 / 167)$ & $37.7(60 / 159)$ & $39.1(66 / 169)$ & 0.96 \\
\hline $61 \mathrm{~d}$ & $34.1(57 / 167)$ & $35.4(56 / 158)$ & $34.5(58 / 168)$ & 0.97 \\
\hline $\begin{array}{l}\text { Pregnant, end of study } \\
\text { Pregnancy loss }\end{array}$ & $75.5(126 / 167)$ & $75.5(120 / 159)$ & $74.6(126 / 169)$ & 0.93 \\
\hline 31 to $61 \mathrm{~d}$ & $10.9(7 / 64)$ & $5.1(3 / 59)$ & $10.8(7 / 65)$ & 0.45 \\
\hline
\end{tabular}

${ }^{1}$ Control $=$ cows inseminated at detected estrus from $\mathrm{d} 14$ to 31 or resynchronized with a timed AI protocol upon a diagnosis of nonpregnancy on d 31 after AI; CIDR-G = insertion of an intravaginal progesterone insert from d 14 to 21 after AI, with AI at estrus from d 21 to 24 and initiation of the timed AI on d 24 in those not in estrus; CIDR-G + ECP = same treatment as CIDR-G but with an injection of $1 \mathrm{mg}$ of estradiol cypionate at the time of intravaginal progesterone insert removal.

${ }^{2}$ One cow from the CIDR-G treatment and 1 cow from the CIDR-G + ECP treatment were diagnosed as pregnant on $\mathrm{d} 31$ but culled before the final pregnancy diagnosis on $\mathrm{d} 61$ after AI.

differences with $P \leq 0.05$ were considered significant and $0.05<P \leq 0.10$ were considered a tendency toward difference.

\section{RESULTS}

As expected based on blocking criteria, when cows were initially enrolled in the control, CIDR-G, and CIDR-G + ECP treatments, the average lactation number $(2.5,2.5$, and 2.4$)$, number of $\mathrm{AI}(1.66,1.63$, and 1.67), days postpartum (124.0, 118.6, and 116.7), BCS $(2.78,2.83$, and 2.73$)$, and milk yield $(43.2,42.7$, and $42.9 \mathrm{~kg} / \mathrm{d})$ were all similar $(P>0.10)$. The median intervals from previous AI to administration of treatments following all AI were 14, 14, and 14 for the control, CIDR-G, and CIDR-G + ECP treatments, respectively. Retention of CIDR inserts was similar $(P=0.72)$ between the CIDR-G and CIDR-G + ECP treatments and averaged $95.2 \%(634 / 666)$ during the $7-\mathrm{d}$ administration period.

The proportion of cows with an active CL on d 14, 21 , and 24 , based on progesterone concentration of $\geq 1$ $\mathrm{ng} / \mathrm{mL}$, were similar for all treatments for the PAI and all AI and averaged, respectively, 93.3 (462/495), 70.3 (348/495), and 53.7\% (266/495) for the PAI, and 92.9 (930/1,001), $65.2(653 / 1,001)$, and $47.6 \%(476 / 1,001)$ for all AI. Incidence of luteolysis from d 14 to 21,21 to 24 , and 14 to 24 , as indicated by a drop in progesterone concentration to $<1 \mathrm{ng} / \mathrm{mL}$, were similar for all treatments for the PAI and averaged 24.7 (114/462), 23.6 (82/348), and $42.4 \%$ (196/462), respectively. Incidence of luteolysis from d 14 to 21 and overall incidence of luteolysis from d 14 to 24 were also similar among all treatments of all AI and averaged 29.8 (277/930) and $48.8 \%$ (454/930), respectively; however, incidence of luteolysis for all AI between d 21 and 24 tended $(P=0.07)$ to be affected by treatment, and was greater $(P=0.03)$ for CIDR-G + ECP than CIDR-G and tended to be greater $(P=0.08)$ than for the control treatment. Luteolysis incidence rates between 21 and $24 \mathrm{~d}$ were 25.4 (54/ 213), 23.4 (51/218), and 32.4\% (72/222) for the control, CIDR-G, and CIDR-G + ECP treatments, respectively.

Conception rates on $\mathrm{d} 31$ and 61 after $\mathrm{AI}$ and pregnancy losses between d 31 and 61 were similar for all treatments for the PAI (Table 1) and all AI (Table 2). Mucus scores were obtained from $634 \mathrm{AI}$ from cows that retained the CIDR insert for $7 \mathrm{~d}$, and the frequencies of scores were $1=0 \% ; 2=16 \% ; 3=60.1 \% ; 4=23.2 \%$; and $5=0.6 \%$. Mucus score did not affect conception rates, and cows with a mucus score of $\leq 3$ had conception rate on d 31 after all $\mathrm{AI}$ similar to $(P=0.17)$ cows with a mucus score of $>3$ (32.5 vs. $38.4 \%)$. Likewise, conception rate on d 31 was similar $(P=0.62)$ for cows with a mucus score of $\leq 3$ or $>3$ for the RAI ( 26.4 vs. $24.2 \%)$. No effect $(P>0.15)$ of mucus score was observed on pregnancy loss between 31 and $61 \mathrm{~d}$ of gestation for all AI or RAI (data not shown).

Estrus was detected accurately in $95.3 \%$ (301/316) of the cows evaluated and was similar $(P=0.70)$ for the control (96.3\%; 104/108), CIDR-G (93.8\%; 91/97), and CIDR-G + ECP $(95.5 \%$; 106/111) treatments. Accuracy of estrus was also similar $(P=0.46)$ for AI performed by the 3 technicians: 1 (97.0\%; 33/34), 2 (94.0\%; 172/ $183)$, and 3 (97.0\%; 96/99).

Treatment affected the EDR of nonpregnant cows in all the intervals evaluated (Table 3). The EDR from d 14 to 21 after AI was smaller $(P<0.01)$ for the CIDR$G$ and CIDR-G + ECP treatments compared with the control treatment. Of the 6 cows from the CIDR-G and CIDR-G + ECP treatments inseminated between d 14 and 21 after AI, 2 were cows with their inserts in place 
Table 2. Effect of the resynchronization protocol on conception rates and pregnancy loss for all AI

\begin{tabular}{llccr}
\hline & \multicolumn{4}{c}{ Treatment $^{1}$} \\
\cline { 2 - 4 } Item & Control & CIDR-G & CIDR-G + ECP & $P$ \\
\hline Conception rate $^{2}$ & $34.6(116 / 335)$ & $33.0(110 / 333)$ & $34.2(114 / 333)$ & 0.92 \\
$31 \mathrm{~d}$ & $31.0(104 / 335)$ & $30.8(102 / 331)$ & $30.3(100 / 330)$ & 0.95 \\
$\begin{array}{l}\text { 61 d } \\
\text { Pregnancy loss }\end{array}$ & $10.3(12 / 116)$ & $5.6(6 / 108)$ & $9.9(11 / 111)$ & 0.35 \\
\hline 1 to 61 d &
\end{tabular}

${ }^{1}$ Control $=$ cows inseminated at detected estrus from d 14 to 31 or resynchronized with a timed AI protocol upon diagnosis of nonpregnancy on d 31 after AI; CIDR-G = insertion of an intravaginal progesterone insert from d 14 to 21 after AI, with AI at estrus from d 21 to 24 and initiation of the timed AI on d 24 in those not in estrus; CIDR-G + ECP = same treatment as CIDR-G but with an injection of $1 \mathrm{mg}$ of estradiol cypionate at the time of intravaginal progesterone insert removal.

${ }^{2}$ Two cows from the CIDR-G treatment and 3 from the CIDR-G + ECP treatment were diagnosed as pregnant on d 31 but culled before a pregnancy reconfirmation on d 61 after AI.

and progesterone concentrations of $>1 \mathrm{ng} / \mathrm{mL}$ and 4 were cows that lost their progesterone inserts and were inseminated when progesterone concentrations were $<1$ $\mathrm{ng} / \mathrm{mL}$. In contrast to EDR from d 14 to 21, EDR between $\mathrm{d} 21$ and 24 after AI was greater $(P<0.01)$ for cows in the CIDR-G and CIDR-G + ECP treatments than for controls. Although a shift occurred in time to estrus (Figure 2), the overall EDR from d 14 to 24 was similar $(P=0.33)$ for all treatments.

Treatment with GnRH on d 24 in CIDR-G and CIDR$\mathrm{G}+\mathrm{ECP}$ cows decreased $(P<0.01)$ the return to estrus from d 24 to 31 after AI. Overall, the EDR from d 14 to 31 after AI was similar for the control and CIDR-G + ECP treatments, and both were greater $(P=0.03)$ than for the CIDR-G treatment. Consequently, a greater $(P=0.03)$ proportion of nonpregnant cows from the CIDR-G treatment received timed AI than from the control and CIDR-G + ECP treatments (Table 3). The inter-AI interval tended $(P=0.08)$ to be affected by treatment, and cows from the CIDR-G + ECP treatment had shorter $(P=0.02)$ reinsemination intervals than control cows, whereas cows in the CIDR-G treatment were intermediate and not different from those in the other treatments.

Ovulation was evaluated for 634 of the 653 RAI (Table 4). Similar to EDR, the ovulation incidence from d 14 to 21 was smaller $(P<0.01)$ for the CIDR-G and CIDR$\mathrm{G}+\mathrm{ECP}$ treatments compared with the control treatment. From d 21 to 24, the ovulation incidence was greater $(P<0.01)$ for the CIDR-G + ECP treatment compared with the control and CIDR-G treatments. However, treatment did not affect $(P>0.10)$ the ovulation incidence from $\mathrm{d} 14$ to $24, \mathrm{~d} 24$ to 31 , or the overall ovulation incidence from d 14 to 31 after PAI. Of the

Table 3. Effect of the resynchronization protocol on estrus-detection rate at different intervals and reinsemination interval for resynchronized AI

\begin{tabular}{|c|c|c|c|c|}
\hline \multirow[b]{2}{*}{ Item } & \multicolumn{3}{|c|}{ Treatment $^{1}$} & \multirow[b]{2}{*}{$P$} \\
\hline & Control & CIDR-G & CIDR-G + ECP & \\
\hline Interval & $\longrightarrow$ & $-\%(\mathrm{n} / \mathrm{n})-$ & - & \\
\hline Day 14 to 21 & $17.7(38 / 215)^{\mathrm{a}}$ & $1.8(4 / 220)^{\mathrm{b}}$ & $0.9(2 / 218)^{b}$ & $<0.01$ \\
\hline Day 21 to 24 & $25.1(54 / 215)^{\mathrm{a}}$ & $39.1(86 / 220)^{b}$ & $45.9(100 / 218)^{b}$ & $<0.01$ \\
\hline Day 14 to 24 & $42.8(92 / 215)$ & $40.9(90 / 220)$ & $46.8(102 / 218)$ & 0.33 \\
\hline Day 24 to 31 & $17.7(38 / 215)^{\mathrm{a}}$ & $6.8(15 / 220)^{\mathrm{b}}$ & $10.1(22 / 218)^{\mathrm{b}}$ & $<0.01$ \\
\hline Day 14 to 31 & $60.5(130 / 215)^{\mathrm{a}}$ & $47.7(105 / 220)^{\mathrm{b}}$ & $56.9(124 / 218)^{\mathrm{a}}$ & 0.03 \\
\hline Timed AI & $39.5(85 / 215)^{\mathrm{a}}$ & $52.3(115 / 220)^{\mathrm{b}}$ & $43.1(94 / 218)^{\mathrm{a}}$ & 0.03 \\
\hline Inter-AI interval, $\mathrm{d}$ & $29.6 \pm 0.51^{\mathrm{a}}$ & $29.0 \pm 0.51^{\mathrm{ab}}$ & $28.1 \pm 0.50^{\mathrm{b}}$ & 0.08 \\
\hline
\end{tabular}

${ }^{\mathrm{a}, \mathrm{b}}$ Superscripts in the same row differ $(P \leq 0.05)$.

${ }^{\mathrm{c}, \mathrm{d}}$ Superscripts in the same row tend to differ $(0.05<P<0.10)$.

${ }^{1}$ Control $=$ cows inseminated at detected estrus from $\mathrm{d} 14$ to 31 or resynchronized with a timed AI protocol upon diagnosis of nonpregnancy on d 31 after AI; CIDR-G = insertion of an intravaginal progesterone insert from d 14 to 21 after AI, with AI at estrus from d 21 to 24 and initiation of the timed AI on d 24 in those not in estrus; CIDR-G + ECP = same treatment as CIDR-G but with an injection of $1 \mathrm{mg}$ of estradiol cypionate at the time of intravaginal progesterone insert removal. 


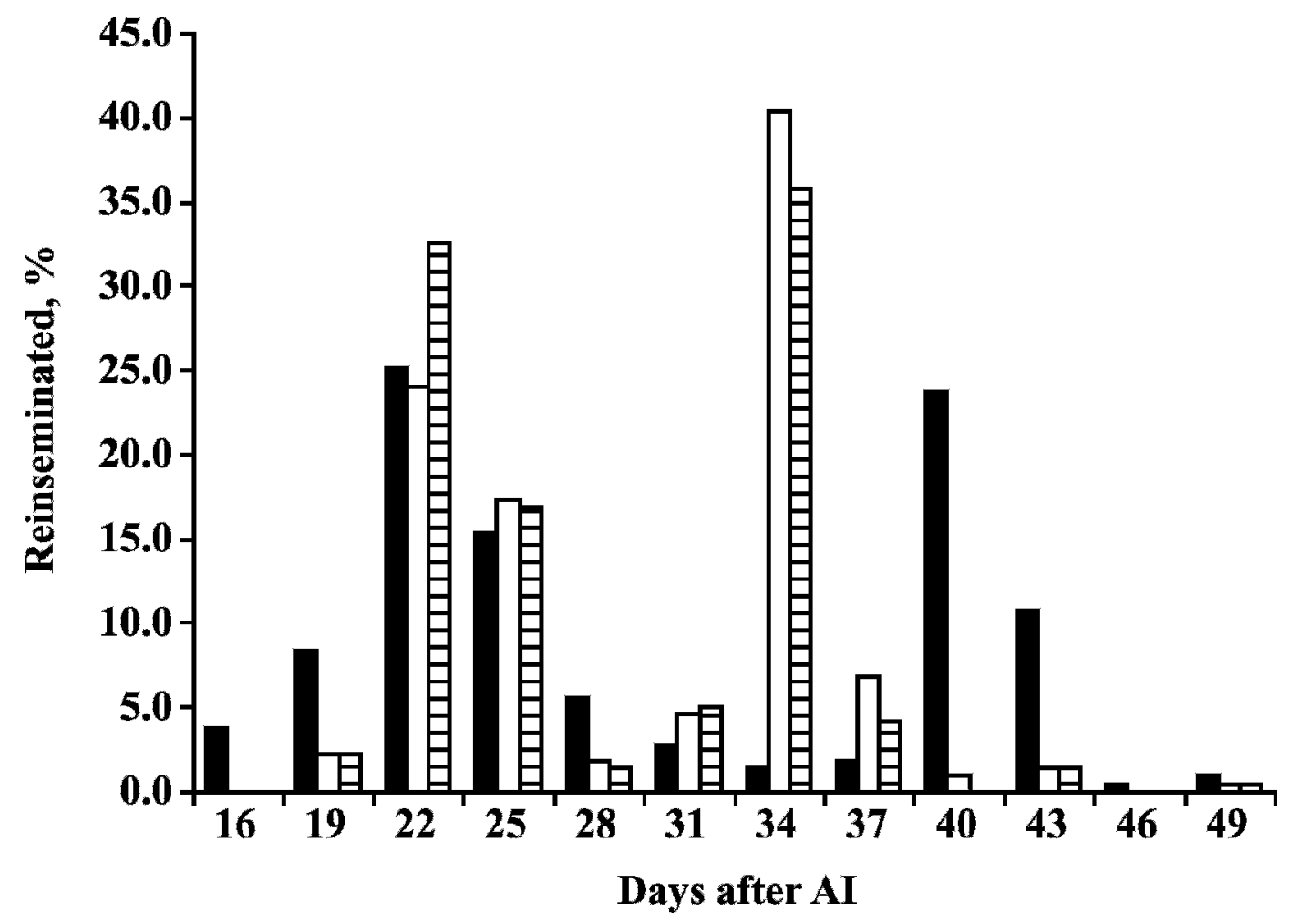

Figure 2. Histogram of days after AI when insemination was performed during the resynchronization period. Control (black bars; $\mathrm{n}=$ $215 \mathrm{AI})=$ reinsemination upon detection of estrus between d 14 and 31 after $\mathrm{AI}$ or resynchronization with a timed AI protocol upon diagnosis of nonpregnancy on d 31 after AI; CIDR-G (white bars; $n=220 \mathrm{AI}$ ) = insertion of an intravaginal insert containing progesterone from d 14 to 21 after AI, with $\mathrm{AI}$ at estrus from d 21 to 24 and initiation of the timed AI protocol on d 24 in those not in estrus; CIDR-G + ECP (striped bars; $\mathrm{n}=218 \mathrm{AI}$ ) = same treatment as CIDR-G but with an injection of $1 \mathrm{mg}$ of estradiol cypionate at the time of intravaginal insert removal.

$232 \mathrm{RAI}$ in which cows were detected in estrus between d 21 and 24 and ovulation was evaluated, 81.5\% (189/ 232) of the estruses were followed by ovulation. Resynchronization method did not influence $(P=0.28)$ the proportion of estruses detected between 21 and $24 \mathrm{~d}$ followed by ovulation, and were $78.9 \%(41 / 52), 77.7 \%$ (66/85), and $86.3 \%$ (82/95) for the control, CIDR-G, and CIDR-G + ECP treatments, respectively.

There was no effect of resynchronization protocol on the conception rates on $\mathrm{d} 31$ or 61 after $\mathrm{AI}$ or on the

Table 4. Effect of the resynchronization protocol on incidence of ovulations at different intervals for resynchronized AI

\begin{tabular}{|c|c|c|c|c|}
\hline \multirow[b]{2}{*}{ Item } & \multicolumn{3}{|c|}{ Treatment $^{1}$} & \multirow[b]{2}{*}{$P$} \\
\hline & Control & CIDR-G & CIDR-G + ECP & \\
\hline & & $-\%(\mathrm{n} / \mathrm{n})-$ & 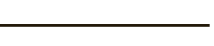 & \\
\hline Day 14 to 21 & $12.7(27 / 213)^{\mathrm{a}}$ & $1.9(4 / 212)^{\mathrm{b}}$ & $1.4(3 / 209)^{\mathrm{b}}$ & $<0.01$ \\
\hline Day 21 to 24 & $33.3(71 / 213)^{\mathrm{a}}$ & $41.0(87 / 212)^{\mathrm{a}}$ & $51.2(107 / 209)^{\mathrm{b}}$ & $<0.01$ \\
\hline Day 14 to 24 & $46.0(98 / 213)$ & $42.9(91 / 212)$ & $52.6(110 / 209)$ & 0.18 \\
\hline Day 24 to 31 & $27.7(59 / 213)$ & $28.8(61 / 212)$ & $28.2(59 / 209)$ & 0.95 \\
\hline Day 14 to 31 & $73.7(157 / 213)$ & $71.7(152 / 212)$ & $80.4(168 / 209)$ & 0.14 \\
\hline
\end{tabular}

\footnotetext{
${ }^{\mathrm{a}, \mathrm{b}}$ Superscripts in the same row differ $(P \leq 0.05)$.

${ }^{\mathrm{c}, \mathrm{d}}$ Superscripts in the same row tend to differ $(0.05<P<0.10)$.

${ }^{1}$ Control $=$ cows inseminated at detected estrus from $\mathrm{d} 14$ to 31 or resynchronized with a timed AI protocol upon diagnosis of nonpregnancy on d 31 after AI; CIDR-G = insertion of an intravaginal progesterone insert from d 14 to 21 after AI, with AI at estrus from d 21 to 24 and initiation of the timed AI on d 24 in those not in estrus; CIDR-G + ECP = same treatment as CIDR-G but with an injection of $1 \mathrm{mg}$ of estradiol cypionate at the time of intravaginal progesterone insert removal.
} 
Table 5. Effect of the resynchronization protocol on conception rates and pregnancy loss for the resynchronized AI

\begin{tabular}{lcccr}
\hline & \multicolumn{3}{c}{ Treatment $^{1}$} \\
\cline { 2 - 4 } Item & Control & CIDR-G & CIDR-G + ECP & $P$ \\
\hline Conception rate & $29.2(61 / 209)$ & $26.2(56 / 214)$ & $28.8(61 / 212)$ & 0.77 \\
Day 31 & $26.3(55 / 209)$ & $24.0(51 / 213)$ & $25.1(52 / 207)$ & 0.87 \\
Day 61 & $9.8(6 / 61)$ & $7.3(4 / 55)$ & $7.1(4 / 56)$ & 0.76 \\
Pregnancy loss & Day 31 to 61 &
\end{tabular}

${ }^{1}$ Control $=$ cows inseminated at detected estrus from $d 14$ to 31 or resynchronized with a timed AI protocol upon diagnosis of nonpregnancy on d 31 after AI; CIDR-G = insertion of an intravaginal progesterone insert from d 14 to 21 after AI, with AI at estrus from d 21 to 24 and initiation of the timed AI on d 24 in those not in estrus; CIDR-G + ECP = same treatment as CIDR-G but with an injection of $1 \mathrm{mg}$ of estradiol cypionate at the time of intravaginal progesterone insert removal.

${ }^{2} \mathrm{Six}$ cows from each treatment were sold before pregnancy diagnosis on $\mathrm{d} 31$ after the resynchronized AI.

${ }^{3}$ One cow from the CIDR-G treatment and 5 from the CIDR-G + ECP treatment were diagnosed as pregnant on $\mathrm{d} 31$ but culled before a pregnancy reconfirmation on d 61 after resynchronized AI.

pregnancy loss between d 31 and 61 for the RAI (Table $5)$. In addition, there was no interaction $(P>0.25)$ between treatment and method of AI on the conception rates on d 31 or 61 after AI or on the pregnancy loss between $\mathrm{d} 31$ and 61 for the RAI.

Interval from AI to CIDR insertion affected EDR (Table 6). Cows in which the CIDR was inserted on $d 13$ after AI had the greatest overall EDR, whereas those receiving the insert on $\mathrm{d} 12$ resulted in the lowest overall return to estrus, and the intervals of 14 and 15 $\mathrm{d}$ were intermediate. The interval from AI to CIDR insertion also affected the conception rates of cows that were reinseminated in estrus (Table 6). When intervals were grouped as short (12 and $13 \mathrm{~d}$ ) and long (14 and $15 \mathrm{~d})$, the long interval resulted in smaller $(P=0.03)$ conception rates at 31 and $61 \mathrm{~d}$ after AI.

Time to pregnancy, as evaluated based on the interval from initial study enrollment to conception on d 31 after AI, was not affected $(P=0.94)$ by treatments, and the median and LSM \pm SEM for days to conception were, respectively, 40 and $51.3 \pm 4.4$ for the control treatment, 33 and $53.8 \pm 4.5$ for the CIDR-G treatment, and 34 and $56.7 \pm 5.1$ for the CIDR-G + ECP treatment (Figure 3). No interaction between treatment and other explanatory variables evaluated was observed for time to pregnancy.

Table 6. Effect of days from AI when cows received the intravaginal progesterone insert on estrus-detection rates, conception rates, and pregnancy loss for reinseminations performed upon detection of estrus in the CIDR-G and CIDR-G + ECP treatments ${ }^{1}$

\begin{tabular}{|c|c|c|c|c|c|c|}
\hline \multirow[b]{2}{*}{ Item } & \multicolumn{4}{|c|}{ Days from AI } & \multicolumn{2}{|c|}{$P^{2}$} \\
\hline & 12 & 13 & 14 & 15 & $\mathrm{C} 1$ & $\mathrm{C} 2$ \\
\hline \multicolumn{7}{|l|}{ Estrus-detection rate } \\
\hline Day 14 to 21 & $1.34(2 / 149)$ & $1.75(1 / 57)$ & $1.46(2 / 137)$ & $1.05(1 / 95)$ & 0.98 & 0.86 \\
\hline Day 21 to 24 & $33.6(50 / 149)^{\mathrm{a}}$ & $47.4(27 / 57)^{\mathrm{ab}}$ & $48.2(66 / 137)^{\mathrm{b}}$ & $45.3(43 / 95)^{\mathrm{ab}}$ & 0.02 & 0.02 \\
\hline Day 24 to 31 & $10.1(15 / 149)^{\mathrm{ab}}$ & $17.5(10 / 57)^{\mathrm{a}}$ & $4.4(6 / 137)^{\mathrm{b}}$ & $6.3(6 / 95)^{\mathrm{b}}$ & 0.04 & 0.02 \\
\hline Day 14 to 31 & $45.0(67 / 149)^{\mathrm{a}}$ & $66.7(38 / 57)^{\mathrm{b}}$ & $54.0(74 / 137)^{\mathrm{ab}}$ & $52.6(50 / 95)^{\mathrm{ab}}$ & 0.05 & 0.57 \\
\hline \multicolumn{7}{|l|}{ Conception rate ${ }^{3}$} \\
\hline Day 31 & $33.3(22 / 66)$ & $35.1(13 / 37)$ & $23.3(17 / 73)$ & $17.4(8 / 46)$ & 0.17 & 0.03 \\
\hline Day 61 & $30.2(19 / 63)$ & $33.3(12 / 36)$ & $19.4(14 / 72)$ & $17.4(8 / 46)$ & 0.19 & 0.03 \\
\hline \multicolumn{7}{|l|}{ Pregnancy loss } \\
\hline Day 31 to 61 & $0.0(0 / 19)$ & $0.0(0 / 12)$ & $12.5(2 / 16)$ & $0.0(0 / 8)$ & - & - \\
\hline
\end{tabular}

${ }^{\mathrm{a}, \mathrm{b}}$ Superscripts in the same row differ $(P \leq 0.05)$.

${ }^{\mathrm{c}, \mathrm{d}}$ Superscripts in the same row tend to differ $(0.05<P<0.10)$.

${ }^{1} \mathrm{CIDR}-\mathrm{G}=$ insertion of an intravaginal progesterone insert from d 14 to 21 after AI, with AI at estrus from d 21 to 24 and initiation of the timed AI on d 24 in those not in estrus; CIDR-G + ECP = same treatment as CIDR-G but with an injection of $1 \mathrm{mg}$ of estradiol cypionate at the time of intravaginal progesterone insert removal.

${ }^{2} \mathrm{C} 1$ = each day evaluated independently; $\mathrm{C} 2=\mathrm{d} 12$ and 13 vs. $\mathrm{d} 14$ and 15.

${ }^{3}$ Three, 1 , and 1 cows receiving the intravaginal insert on $\mathrm{d} 12,13$, and 14 , respectively, were diagnosed as pregnant on d 31 but were culled before a pregnancy reconfirmation on $\mathrm{d} 61$. 


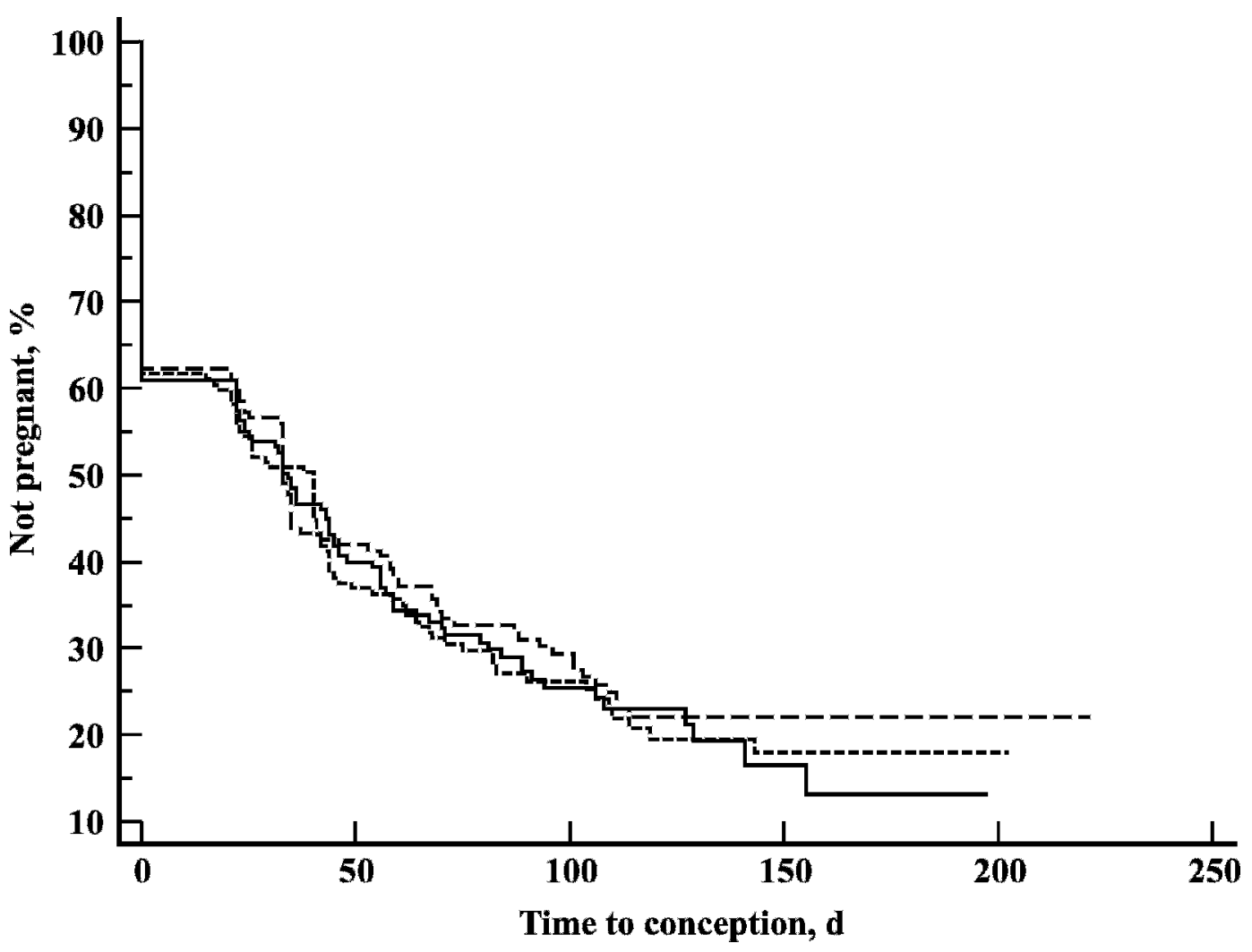

Figure 3. Survival analysis of time to pregnancy in dairy cows subjected to 3 treatments. Control $(n=167$; dotted line $)=$ reinsemination upon detection of estrus between d 14 and 31 after AI or resynchronization with a timed AI protocol upon diagnosis of nonpregnancy on d 31 after AI; CIDR-G $(\mathrm{n}=159$; dashed line $)=$ insertion of an intravaginal insert containing progesterone from d 14 to 21 after AI, with AI at estrus from d 21 to 24 and initiation of the timed AI protocol on d 24 in those not in estrus; CIDR-G + ECP ( $\mathrm{n}=167$; solid line) = same treatment as CIDR-G but with an injection of $1 \mathrm{mg}$ of estradiol cypionate at the time of intravaginal insert removal. Median and mean $(\mathrm{LSM} \pm \mathrm{SEM}$ ) days to pregnancy were, respectively, 40 and $51.3 \pm 4.4$ for the control treatment, 33 and $53.8 \pm 4.5$ for the CIDR-G treatment, and 34 and $56.7 \pm 5.1$ for the CIDR-G + ECP treatment $(P=0.94)$.

\section{DISCUSSION}

Resynchronization programs are frequently used for the reproductive management of dairy cattle to improve the reinsemination rate of nonpregnant cows and to expedite the interval from nonpregnancy to conception (Caraviello et al., 2006). Previous work has focused on the fertility of dairy cows after a single resynchronization treatment (Chebel et al., 2003; El-Zarkouny and Stevenson, 2004), without considering the time to pregnancy when cows are subjected to the same treatment over time. Fricke et al. (2003) attempted to evaluate pregnancy risk when cows were subjected to resynchronization with $\mathrm{GnRH}$ either before or at the diagnosis of nonpregnancy, but treatments were altered because of a reduced resynchronized pregnancy rate when GnRH was given on d 19 after AI.

The current study evaluated different combinations of hormonal treatments to resynchronize return to estrus and ovulation in dairy cows. Of the total number of intravaginal progesterone inserts used, $4.8 \%$ were lost before completion of the 7-d treatment, which was slightly greater than previously reported (2.7\%; Chenault et al., 2003; Galvão et al., 2004). In contrast, Chenault et al. (2003) observed substantial variation in retention of inserts, from 91.9 to $100 \%$ across 8 locations. Although retention in the current study was smaller than the average retention observed by others, it was still within reported limits.

Analyses of concentrations of progesterone in plasma on d 14, 21, and 24 were valuable to evaluate the possible effect of treatments on the presence of CL and luteolysis, because increases (Chebel et al., 2006) or decreases (Chenault et al., 2003) in the conception rate to the PAI have been observed in previous studies when a progesterone insert was used for resynchronization of return to estrus. Furthermore, a reduction in luteal function has been observed following estradiol injection at progesterone insert removal (El-Zarkouny and Stevenson, 2004). Nevertheless, no differences were observed among treatments on the proportion of cows with 
an active CL on $\mathrm{d} 14$ and 21 after $\mathrm{AI}$ and on the incidence of luteolysis from d 14 to 21 for the PAI or all AI, indicating that there was no effect of treatment with the progesterone insert between d 14 and 21 after AI on the presence or maintenance of a CL. However, the incidence of luteolysis between d 21 and 24 increased in cows receiving estradiol when all AI were evaluated. El-Zarkouny and Stevenson (2004) observed that injection of estradiol reduced concentrations of progesterone in the days after treatment; however, similar to the current study, the potentially negative effects of estrogen on embryonic survival did not persist past the early embryonic period. Estradiol is known to stimulate expression of oxytocin receptors in the uterus and might increase uterine responsiveness to oxytocin, thereby causing prostaglandin release and CL regression (Silvia et al., 1991). It is possible that the treatment of cows with ECP on d 21 after AI accelerated the process of CL regression from d 21 to 24 in CIDR-G + ECP cows that were already undergoing luteolysis, because ECP had no deleterious effect on conception rates on $\mathrm{d} 31$ or 61 after AI.

Similar conception rates on d 31 and 61 after AI among resynchronization methods indicate that treatment of lactating dairy cows of unknown pregnancy status with a progesterone insert, ECP, and GnRH did not affect the established pregnancy, and are in accordance with previous studies in which GnRH (Chebel et al., 2003; Fricke et al., 2003) and a progesterone insert and ECP (El-Zarkouny and Stevenson, 2004) were administered to lactating dairy cows of unknown pregnancy status. Intriguingly, the use of intravaginal inserts containing progesterone to resynchronize return to estrus in dairy cows has also been found to decrease (Chenault et al., 2003) or increase (Chebel et al., 2006) the conception rate. The detrimental effect of intravaginal progesterone inserts during resynchronization on fertility observed by Chenault et al. (2003) was associated with the vaginal mucus, in which a greater mucous score suggestive of severe vaginitis resulted in a smaller pregnancy rate compared with cows with lower scores (Chenault et al., 2003). Herein, there was no effect of treatment or mucous score on conception rates or on pregnancy losses. Both Chebel et al. (2006) and ElZarkouny and Stevenson (2004) observed that administration of an intravaginal progesterone insert for $7 \mathrm{~d}$ improved embryonic survival after $29 \mathrm{~d}$ of gestation. Interestingly, the work of Chebel et al. (2006) demonstrated that cows presynchronized with a progesterone insert and subsequently resynchronized with another insert between 14 and $21 \mathrm{~d}$ after AI had increased conception rates on $\mathrm{d} 31$ and 60 after AI. In a meta-analysis, Mann and Lamming (1999) observed that supplemental progesterone increased conception rates when adminis- tered before d 6 after AI in lactating dairy cows. Similarly, treatment with a progesterone-releasing intravaginal device containing $1.55 \mathrm{~g}$ of progesterone from gestation d 36 to 64 increased fetal survival in lactating dairy cows (Lopez-Gatius et al., 2004). Although the results of use of progesterone inserts after $\mathrm{AI}$ on conception rate are conflicting, the observations from the current study, in which cows were subjected to the same treatment several times, indicated that using a progesterone insert between 14 and $21 \mathrm{~d}$ after AI was neither detrimental to pregnancy, nor did it improve embryonic or fetal survival.

As expected, estrous expression decreased while the CIDR insert was present because of the negative effect of progesterone on expression of estrus; however, because of inaccurate detection of estrus and loss of the intravaginal insert, a small percentage of cows were detected in estrus and reinseminated between $\mathrm{d} 14$ and 21 after AI in the CIDR-G and CIDR-G + ECP treatments. After removal of the intravaginal progesterone insert, estrus was effectively synchronized between d 21 and 24 after AI, with $42.5 \%$ of the cows in the CIDR$\mathrm{G}$ and CIDR-G + ECP treatments returning to estrus compared with only $25.1 \%$ of control cows. The EDR from d 14 to 24 after AI was similar for all treatments; however, a smaller proportion of CIDR-G cows returned to estrus between 14 and $31 \mathrm{~d}$ after AI compared with cows in the CIDR-G + ECP and control treatments.

The impact of using a CIDR insert to synchronize the return to estrus in nonpregnant dairy cows is somewhat conflicting. Some studies reported a greater EDR in a 3-d observation period after CIDR removal (Chenault et al., 2003). On the other hand, when EDR was evaluated during the entire study period, including when cows had the CIDR in place, the pattern of return was altered, but overall EDR was similar for cows treated or not treated with the progesterone insert (El-Zarkouny and Stevenson, 2004; Chebel et al., 2006). Cows that received CIDR inserts had a shorter period for detection of estrus because they were not expected to display estrus during the 7-d treatment. Furthermore, CIDR$G$ and CIDR-G + ECP cows not in estrus received GnRH on $\mathrm{d} 24$, which is known to reduce estrous expression (Chebel et al., 2003).

Cows in the CIDR-G and CIDR-G + ECP treatments that received the CIDR on 12 after AI had the smallest EDR in the $4 \mathrm{~d}$ following insert removal, which compromised the overall EDR up to d 31. These results were expected because cows receiving the CIDR on $\mathrm{d} 12$ were observed for estrus from d 19 to 23 after the previous AI. Because most cows return to estrus spontaneously on d 21 to 25 (Figure 2, control cows), limiting observation of estrus to before $\mathrm{d} 23$ is expected to reduce EDR. This could have affected the overall EDR in cows receiv- 
ing the CIDR compared with control cows in the current study. Furthermore, treatment with GnRH 3 to 4 d after CIDR removal might have caused ovulation of the dominant follicle and consequently decreased estradiol concentrations in the blood, hence inhibiting induction of estrus. To support this idea, we observed that although the ovulation incidence was similar for all treatments between d 24 and 31 after AI, the EDR for the same period was decreased for cows receiving the CIDR$\mathrm{G}$ and CIDR-G + ECP treatments.

The fact that treatment with ECP in cows receiving a CIDR insert reestablished overall EDR compared with controls is noteworthy. Treatment of lactating dairy cows with ECP at CIDR removal has been found to increase estradiol concentrations in plasma (El-Zarkouny and Stevenson, 2004), and the use of ECP in timed AI protocols has been shown to effectively synchronize estrus and ovulation in lactating dairy cows (Pancarci et al., 2002; Galvão et al., 2004). When given after induction of luteolysis, ECP increased estrous detection in dairy cows (Pancarci et al., 2002), but the effects of estrogen to increase the display of estrus following CIDR removal have not been clearly demonstrated, although it was previously shown to be numerically greater for cows receiving estradiol (El-Zarkouny and Stevenson, 2004). Our results indicate that use of ECP at progesterone insert removal helped to maintain estrous detection in nonpregnant cows and compensated for the reduced overall EDR when the insert was used alone.

Although a decrease in EDR after administration of GnRH on d 24 was anticipated (Chebel et al., 2003), it was also expected that initiating the resynchronization protocol for timed AI before a diagnosis of nonpregnancy would expedite reinsemination in cows receiving the CIDR-G and CIDR-G + ECP treatments. For control cows, $60.5 \%$ of the resynchronized cows were observed in estrus before a diagnosis of nonpregnancy, and $83 \%$ of the cows that ovulated (130/157) between 14 and 31 $\mathrm{d}$ after the RAI were observed in estrus during the same period, with $17 \%$ of the ovulations not followed by detected estrous behavior. Because of this high estrous detection between $\mathrm{d} 14$ and 31 for control cows, only a small positive effect of the CIDR-G + ECP treatment on the insemination interval was observed. Therefore, under the conditions of the current study, the use of a CIDR insert combined with administration of GnRH 7 $d$ before the diagnosis of nonpregnancy did not improve the return to estrus or shorten the reinsemination interval; however, the addition of ECP at the time of CIDR removal reduced the inter-AI interval $1.5 \mathrm{~d}$ because of similar EDR and initiation of the timed AI $7 \mathrm{~d}$ earlier. When timed AI was implemented in 2 herds with distinct reproductive performance, the benefits from a sys- tematic breeding program were more clearly demonstrated in the herd with a poor EDR (Tenhagen et al., 2004). Therefore, it is plausible to suggest that benefits to reproductive performance from aggressive resynchronization methods such as the use of CIDR or CIDR + ECP treatment combined with administration of GnRH before a diagnosis of nonpregnancy could be expected in herds with poor EDR.

The observed effects of days from AI at CIDR insertion on EDR and conception rates were expected. Extended periods of progesterone treatment resulted in tighter synchronization of estrus but reduced fertility, whereas shorter periods of treatment with progesterone inserts decreased synchrony but alleviated the negative effect on fertility (Roche et al., 1999). In the absence of a CL, the low concentration of progesterone resulting from the progesterone insert increases LH pulse frequency (Kojima et al., 1992), which in turn leads to the development of persistent follicles and a reduction in conception rates after AI (Mihm et al., 1994). It was observed that only when the CIDR was inserted on d 12 after $\mathrm{AI}$ was the return to estrus compromised, and initiation of the resynchronization protocol with the CIDR inserted between $d 14$ and 15 decreased conception rates compared with initiation between $d 12$ and 13 after AI. Therefore, these data indicate that the interval between $\mathrm{AI}$ and initiation of a resynchronization protocol based on the CIDR insert was 12 to $13 \mathrm{~d}$ because of the similar return to estrus compared with the 14- to 15-d interval but increased resynchronized conception rates.

In summary, resynchronizing lactating dairy cows of unknown pregnancy status with a CIDR insert, ECP, and $\mathrm{GnRH}$ was not harmful to the established pregnancy. Use of the CIDR insert plus early administration of GnRH decreased EDR but did not affect the time to pregnancy. The addition of ECP at the time of progesterone insert removal maintained overall EDR and reduced the interval between AI compared with cows not resynchronized until diagnosed as nonpregnant. Because the progesterone insert prevented cows from displaying estrus during the 7-d treatment period, the risk for a reduced resynchronized conception rate in cows inseminated at estrus was observed when it was inserted on d 14 and 15 after AI, likely because of persistent follicles, and insertion on d 13 resulted in a maximum return to estrus and a resynchronized conception rate in cows inseminated in estrus. Finally, the resynchronization protocols used in the current study did not reduce the time to pregnancy, and benefits from such programs should not be expected in herds with estrous detection similar to that observed for cows in the control group. 


\section{ACKNOWLEDGMENTS}

The authors wish to thank the staff of the Corcoran State Prison Dairy for use of their cows and facilities. Our gratitude is extended to Frank Hurtig and Joe Dedrickson of Merial for providing the Cystorelin used in this study and Lorin D. Warnick for statistical advice. This research was partially supported by National Research Initiative Competitive Grant no. 2004-3520314137 from the USDA Cooperative State Research, Education, and Extension Service.

\section{REFERENCES}

Caraviello, D. Z., K. A. Weigel, P. M. Fricke, M. C. Wiltbank, M. J. Florent, N. B. Cook, K. V. Nordlund, N. R. Zwald, and C. L. Rawson. 2006. Survey of management practices on reproductive performance of dairy cattle on large US commercial farms. J. Dairy Sci. 89:4723-4735.

Chebel, R. C., J. E. P. Santos, R. L. Cerri, K. N. Galvão, S. O. Juchem, and W. W. Thatcher. 2003. Effect of resynchronization with GnRH on $\mathrm{d} 21$ after artificial insemination on pregnancy rate and pregnancy loss in lactating dairy cows. Theriogenology 60:1389-1399.

Chebel, R. C., J. E. P. Santos, R. L. A. Cerri, H. M. Rutigliano, and R. G. S. Bruno. 2006. Reproduction in dairy cows following progesterone insert presynchronization and resynchronization protocols. J. Dairy Sci. 89:4205-4219.

Chenault, J. R., J. F. Boucher, K. J. Dame, J. A. Meyer, and S. L. Wood-Follis. 2003. Intravaginal progesterone insert to synchronize return to estrus of previously inseminated dairy cows. J. Dairy Sci. 86:2039-2049.

El-Zarkouny, S. Z., and J. S. Stevenson. 2004. Resynchronizing estrus with progesterone or progesterone plus estrogen in cows of unknown pregnancy status. J. Dairy Sci. 87:3306-3321.

Ferguson, J. D., D. T. Galligan, and N. Thomsen. 1994. Principal descriptors of body condition score in Holstein cows. J. Dairy Sci. 77:2695-2703.

Fricke, P. M., D. Z. Caraviello, K. A. Weigel, and M. L. Welle. 2003. Fertility of dairy cows after resynchronization of ovulation at three intervals following first timed insemination. J. Dairy Sci. 86:3941-3950.

Galvão, K. N., J. E. P. Santos, S. O. Juchem, R. L. Cerri, A. C. Coscioni, and M. Villaseñor. 2004. Effect of addition of a progesterone intra- vaginal insert to a timed insemination protocol using estradiol cypionate on ovulation rate, pregnancy rate, and late embryonic loss in lactating dairy cows. J. Anim. Sci. 82:3508-3517.

Kojima, N., T. T. Stumpf, A. S. Cupp, L. A. Werth, M. S. Roberson, M. W. Wolfe, R. J. Kittok, and J. E. Kinder. 1992. Exogenous progesterone and progestins as used in estrous synchrony regimens do not mimic the corpus luteum in regulation of luteinizing hormone and 17 beta-estradiol in circulation of cows. Biol. Reprod. 47:1009-1017.

López-Gatius, F., P. Santolaria, J. L. Yaniz, and R. H. Hunter. 2004. Progesterone supplementation during the early fetal period reduces pregnancy loss in high-yielding dairy cattle. Theriogenology 62:1529-1535.

Lopez, H., L. D. Satter, and M. C. Wiltbank. 2004. Relationship between level of milk production and estrous behavior of lactating dairy cows. Anim. Reprod. Sci. 81:209-223.

Macmillan, K. L., V. K. Taufa, D. R. Barnes, A. M. Day, and R. Henry. 1988. Detecting estrus in synchronized heifers using tail paint and aerosol riddle. Theriogenology 30:1099-1114.

Mann, G. E., and G. E. Lamming. 1999. The influence of progesterone during early pregnancy in cattle. Reprod. Domest. Anim. 34:269-274.

Mihm, M., A. Baguisi, M. P. Boland, and J. F. Roche. 1994. Association between the duration of dominance of the ovulatory follicle and pregnancy rate in beef heifers. J. Reprod. Fertil. 102:123-130.

NRC. 2001. Nutrient Requirements of Dairy Cattle. 7th rev. ed., Natl. Acad. Sci. Washington, DC.

Pancarci, S. M., E. R. Jordan, C. A. Risco, M. J. Schouten, F. L. Lopes, F. Moreira, and W. W. Thatcher. 2002. Use of estradiol cypionate in a presynchronized timed artificial insemination program for lactating dairy cattle. J. Dairy Sci. 85:122-131.

Pursley, J. R., M. O. Mee, and M. C. Wiltbank. 1995. Synchronization of ovulation in dairy cows using $\mathrm{PGF}_{2 \alpha}$ and $\mathrm{GnRH}$. Theriogenology 44:915-923.

Roche, J. F., E. J. Austin, M. Ryan, M. O'Rourke, M. Mihm, and M. G. Diskin. 1999. Regulation of follicle waves to maximize fertility in cattle. J. Reprod. Fertil. Suppl. 54:61-71.

SAS Institute. 2003. SAS/STAT. Release 9.1. SAS Institute Inc., Cary, NC.

Silvia, W. J., G. S. Lewis, J. A. McCracken, W. W. Thatcher, and L. Wilson, Jr. 1991. Hormonal regulation of uterine secretion of prostaglandin $\mathrm{F}_{2 \alpha}$ during luteolysis in ruminants. Biol. Reprod. 45:655-663.

Tenhagen, B. A., M. Drillich, R. Surholt, and W. Heuwieser. 2004. Comparison of timed AI after synchronized ovulation to AI at estrus: Reproductive and economic considerations. J. Dairy Sci. 87:85-94. 